\title{
Regional-scale risk assessment methodology using the Relative Risk Model (RRM) for surface freshwater aquatic ecosystems in South Africa
}

\author{
GC O'Brien ${ }^{1 *}$ and V Wepener ${ }^{2}$ \\ ${ }^{1}$ Water Research Group, School of Environmental Sciences and Development, North West University, Private Bag X6001, \\ Potchefstroom 2520, South Africa \\ ${ }^{2}$ Centre for Aquatic Research, Zoology Department, University of Johannesburg, PO Box 524, Auckland Park 2006, South Africa
}

\begin{abstract}
To maximise the long-term use of limited ecosystem services in South Africa, managers continually require approaches to optimise the establishment of balances between the use and protection of ecosystems to ensure sustainability. Surface freshwater aquatic ecosystems are dynamic and difficult to manage effectively. Sound management protocols that can identify and rank threats to these ecosystems are urgently required. The Regional-Scale Risk Assessment approach is carried out on a spatial scale and allows for the consideration of multiple sources of multiple stressors affecting multiple endpoints, with the inclusion of local ecosystem dynamics and the characteristics of the landscape that may affect the risk estimate. This paper presents an integrated approach to carry out regional-scale ecological risk assessments using a Relative Risk Model (RRM) adapted for South African conditions. The RRM consists of 10 procedural steps that are relatively easily applied. The use and application of the RRM within South Africa has the potential to provide resource users, resource conservators and regulators of surface aquatic ecosystems with a range of benefits. These benefits include the establishment of a validated, structured methodology that is sensitive to the dynamics of individual case studies, extremely informative, locally applicable and internationally comparable with other RRM assessments. The use of the RRM approach in South Africa has many advantages that outweigh some disadvantages. This approach has the potential to substantially contribute towards the ease and effectiveness of management of the balance between the use and protection of aquatic ecosystems in South Africa.
\end{abstract}

Keywords: Surface aquatic ecosystems, Regional-Scale Risk Assessment, Relative Risk Model

\section{Introduction}

The development of human civilisation has been totally dependent on the use and associated availability of aquatic ecosystem services (Costanza, 1997; Davies and Day, 1998; Palmer et al., 2002). Ecosystem services have provided mankind with a vast range of documented economic and social benefits (Palmer et al., 2002; Costanza, 1997). To maximise the long-term use of available services, resource managers require methods to establish balances between the use and protection of ecosystems to ensure sustainability (National Water Act, RSA, 1998a; DWAF, 2004). Within South Africa the aim of water resource management is to achieve the sustainable use of water for the benefit of all users (RSA, 1998a). Aquatic ecosystems are dynamic and often difficult to manage effectively. Although difficult, it is vitally important to the continued survival and development of human communities that the use of aquatic ecosystem services are managed effectively (Palmer et al., 2002).

In South Africa and abroad, ecological risk assessment (ERA) methodologies have been established to identify and rank threats to surface aquatic ecosystems in relation to established management objectives (Suter, 1993; Murray and Claassen, 1999; DWAF, 2004). An ERA is the process of assigning magnitudes and probabilities to the adverse effects of anthropogenic activities or natural catastrophes, which are

\footnotetext{
* To whom all correspondence should be addressed.

용 +27 18 2992493; fax: +27 182992370 ;

e-mail: Gordon.obrien@nwu.ac.za

Received 10 October 2011; accepted in revised form 18 April 2012
}

referred to as hazards (Suter, 1993). The identification of a hazard, the magnitude of the hazard and the related uncertainty results in the formulation of risk. Risk, therefore, is the probability or likelihood of a prescribed undesired effect occurring and impacting an environment (Suter, 1993). The ERA method is a structured approach that describes, explains and organises scientific facts, laws and relationships, thereby providing a sound basis to develop sufficient protection measures for the environment and which facilitates the development of utilisation strategies for the environment (Moosa, 2001). It is a process that evaluates the likelihood that adverse effects may occur, or are occurring, as a result of exposure to one or more stressors (Suter, 2001). As a result, it is concerned with the causal relationship between stressors and effects and deals with the consequences of alternative decisions. Although the application of the ERA approach in South Africa is limited, the approach forms the dominant framework for technical support to environmental regulation endeavours in many industrialised democracies (Suter, 2001). The nature and potential of described effects of environmental stressors in terms of ERAs provide environmental information in the socio-economic context that drives management and environment-based decision making (Suter, 2001).

Traditional ERA methods generally evaluate the interactions of stressors that occur within or are released into the environment, receptors (biota) in that environment, and the receptors' response to the stressors (Landis and Wiegers, 1997). Measurements of exposure between stressors and receptors, and effects measured between stressor and receptors, quantify the degree of interaction between these components. Traditional ERA approaches have primarily addressed 
the potential risk of a single or a small number of chemicals impacting on a limited number of ecological endpoints. This has historically limited the application of the ERA methodology in complex ecosystems where numerous use activities or sources and associated stressors affect numerous receptors (Claassen et al., 2001). To address the limitations of this basic ERA approach, Landis and Wiegers (1997) developed an amended ERA approach, i.e. the Regional-Scale Risk Assessment that makes use of the Relative Risk Model (RRM). The Regional-Scale Risk Assessment is implemented on a large spatial scale and facilitates the consideration of multiple sources of multiple stressors affecting multiple endpoints, including the ecosystem dynamics and characteristics of the landscape that may affect the risk estimate (Landis and Wiegers, 1997). Following the initial development, the RRM has been refined into the working method which has been tried and tested in numerous ERAs around the world (Landis and Wiegers, 1997; Wiegers et al., 1998; Landis et al., 2000; Luxon, 2000; Walker et al., 2001; Chen and Landis, 2005; Hamamé, 2002; Moraes et al., 2002; Obery and Landis, 2002; Thomas, 2003; Hart Hayes et al., 2004; Colnar and Landis, 2007; Landis and Thomas, 2009; Apitz, 2011). With the opportunity to test the RRM approach through so many case studies the approach has been criticised (Cook et al., 1999, Cormier et al., 2000), validated, and refined into the working method presented by Landis (2005) and Colnar and Landis (2007). From a South African perspective, the value of the RRM lies in its potential to be customised to address the threats of multiple sources of multiple stressors to local habitats and endpoints, thereby contributing towards the objectives of integrated water resource management (IWRM) in South Africa (DWAF, 2004).

The aim of this paper is to present an integrated approach to carry out regional-scale ERAs, contributing to the management of freshwater aquatic ecosystems using an adapted RRM with a hypothetical example for South African conditions. We demonstrate the relationship between the existing ERA guidelines and an adapted RRM and demonstrate how locally accepted line-of-evidence methods can be incorporated and applied in the RRM process.

\section{Comparison between Ecological Risk Assessments and the Relative Risk Method}

The South African ERA (SA ERA) Guidelines (Murray and Claassen, 1999) are based on the traditional ERA (US ERA) method that was developed in the United States (USEPA, 1998). Similarly to the US ERA guidelines, the SA ERA Guidelines consist of a framework of 5 basic stages or phases. These 5 phases are:

1. Agree on objectives

2. Plan assessment

3. Analyse

4. Describe risk

5. Manage risk (USEPA, 1998; Murray and Claassen, 1999; Claassen et al., 2001).

By comparison, the RRM consists of 10 procedural steps that can be aligned with ERA frameworks (Suter, 1993; Landis and Wiegers, 1997; Murray and Claassen, 1999), as indicated in Fig. 1. One noticeable feature of the RRM is the greater emphasis that is placed on the 'Risk characterisation' (US ERA) or 'Describe risk' (SA ERA) phases (Fig. 1). Since the standardised terminology that is applied in RRM could have a different meaning to the South African water resource terms, we present the definitions in Table 1 to avoid confusion. The 10 steps of the RRM are:

1. List the important management goals for the region.

2. Generate a map on which the potential sources and habitats relevant to the established management goals are indicated.

3. Demarcate the map into regions based on a combination of the management goals, sources and habitats.

4. Construct a conceptual model that links the sources of stressors to receptors and to the assessment endpoints.

5. Decide on a ranking scheme to calculate the relative risk to the assessment endpoints

6. Calculate the relative risks.

7. Evaluate uncertainty and sensitivity analysis of the relative rankings.

8. Generate testable hypotheses for future field and laboratory investigations to reduce uncertainties and to confirm the risk rankings.

9. Test the hypotheses that were generated in Step 8 .

10. Communicate the results in a fashion that effectively portrays the relative risk and uncertainty in response to the management goals.

When compared to the ERA, the first 4 steps of the RRM correspond to the initial phases of the ERA frameworks, i.e. the 'Problem formulation' (US ERA) and the 'Plan assessment' phases (SA ERA). These initial steps are essential in ensuring the success of the risk assessment. Small parts of Step 4 and Step 5 of the RRM are closely related to the conventional 'Analyses' phases of the ERA paradigms. They also form part of the 'Risk characterisation' and 'Describe risk' phases of the

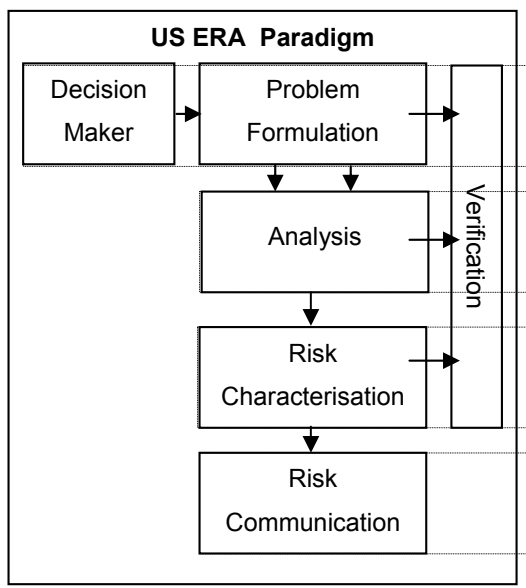

\begin{tabular}{|c|}
\hline RRM \\
Steps: \\
$1,2,3,4$ \\
Step: \\
5 \\
\\
Steps: \\
$6,7,8,9$ \\
\\
Step: \\
10 \\
\hline
\end{tabular}

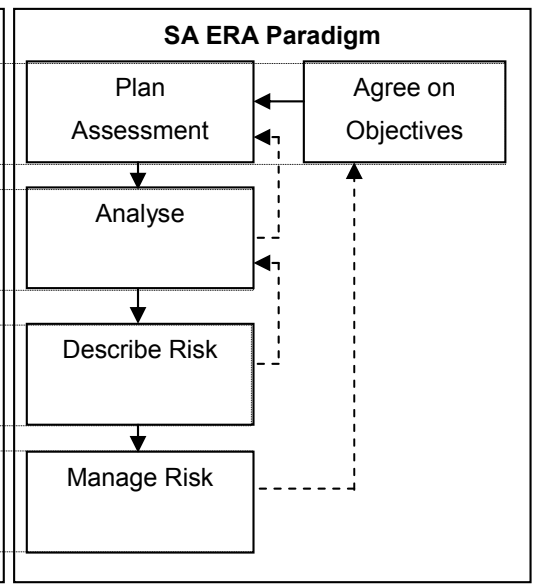

Figure 1

Relationship of the 10 RRM steps to the United States and the South African Ecological Risk Assessment paradigms 


\begin{tabular}{|c|c|}
\hline \multicolumn{2}{|r|}{$\begin{array}{c}\text { Table } 1 \\
\text { Definition of terms used within the context of regional-scale risk assessments }\end{array}$} \\
\hline $\begin{array}{l}\text { Assessment } \\
\text { endpoints }\end{array}$ & $\begin{array}{l}\text { Management goals, objectives or targets. An explicit expression of the environmental value that is } \\
\text { to be protected, operationally defined by an ecological entity and its attributes (USEPA, 1998). }\end{array}$ \\
\hline Ecological entity & $\begin{array}{l}\text { A general term that may refer to a species, a group of species, an ecosystem function or charac- } \\
\text { teristic, or a specific physical habitat. An ecological entity is one component of an assessment } \\
\text { endpoint (USEPA, 1998). }\end{array}$ \\
\hline Habitats & $\begin{array}{l}\text { Location where the receptor or group of receptors of the stressors assessed in the RRM lives. } \\
\text { They are the physical ecosystem component/s that integrate the effects of stressors impacting on } \\
\text { the system (Landis, 2005). }\end{array}$ \\
\hline Lines $\mathrm{c}$ & $\begin{array}{l}\text { Information derived from different sources or by different techniques that can be used to describe } \\
\text { or interpret risk estimates of endpoints (USEPA, 1998). Simply put, a line of evidence includes } \\
\text { any useful set of data and/or associated analyses which can be used to provide information con- } \\
\text { cerning the current state of an endpoint (Landis, 2005). }\end{array}$ \\
\hline Rank & $\begin{array}{l}\text { Unitless measures or scores assigned to source, stressor and/or habitats identified in an RRM } \\
\text { according to a characterised ranking criteria unique to each entity that is usually based on a } \\
\text { weighting factor. Ranks are then used in the calculation of risk in the RRM (adapted from } \\
\text { Landis, 2005). }\end{array}$ \\
\hline Rece & n ecological entity exposed to the stressor (USEPA, 1998). \\
\hline Relati & $\begin{array}{l}\text { RRM method of assigning } \\
\text { manner, i.e. the ranking o }\end{array}$ \\
\hline Risk r & Final risk score of risk regions within the RRM. \\
\hline Sens & $\begin{array}{l}\text { Refers to the robustness of the RRM assessment to withstand external influences (adapted from } \\
\text { Landis, 2005). }\end{array}$ \\
\hline Source & $\begin{array}{l}\text { An entity, action or activity that releases to the environment or imposes on the environment a } \\
\text { chemical, physical, or biological stressor or stressors (USEPA, 1998). }\end{array}$ \\
\hline Stressors & $\begin{array}{l}\text { Any physical, chemical or biological entity that can induce an adverse response to the structure } \\
\text { and function of an ecosystem (USEPA, 1998). }\end{array}$ \\
\hline Uncertainty & $\begin{array}{l}\text { Associated with the RRM analyses, uncertainty relates to there being a lack of sufficient knowl- } \\
\text { edge within component/s of assessment to confidently accept the outcome of the assessment, in as } \\
\text { much as the confidence of the outcome of the assessment should be considered in relation to the } \\
\text { uncertainty of the assessment or components of the assessment (adapted from Landis, 2005). }\end{array}$ \\
\hline
\end{tabular}

ERA. The 'Conceptual model' (RRM Step 4) is based on characterised relationships between the source-stressor-habitats or receptor locations within the ecosystem with associated effects (Landis, 2005). Determination of the 'Ranking scheme' (Step 5) of the RRM makes use of a large quantity of known or generated data relating to the intensity, amount or severity of stressors and habitats, and what is known regarding the potential outcomes of these relationships (Landis, 2005). The 'Conceptual model' and the 'Ranking scheme' steps of the RRM are related to the 'Risk characterisation' or 'Describe risk' phases of the ERA. These steps include the calculation of 'Relative risks', the 'Analyses of the uncertainty and sensitivity' and then the 'Generation of testable hypotheses' (Steps 6 to 8) components. Finally, should the risk outcomes require validation, Step 9 can be implemented, which includes the application of various lines-of-evidence to test the hypotheses generated in Step 8. The last step (Step 10) consists of 3 components which relate to the 'Risk communication' (US ERA) or the 'Manage risk' (SA ERA) phases. The 3 components of risk assessment and the steps taken by risk managers to implement the findings of the risk assessment are as follows:

- Generate maps of the risk regions with the associated sources, land-uses, habitats, and the spatial distribution of the assessment endpoints (Landis, 2005).
- Present a regional comparison of the relative risk, their causes, the patterns of impacts to the assessment endpoints, and the associated uncertainty. These regional comparisons and estimates of the contribution of each source and stressor create a spatially explicit risk hypothesis (Landis, 2005).

- Develop a model of source-habitat-impact that can be used to ask what-if questions about the different scenarios that are potential options in the environmental management (Landis, 2005).

To allow for the outcomes of RRM assessments to be comparable to existing ERA outcomes it is recommended that a traditional ERA format be selected to present the findings of an RRM assessment (Obery and Landis, 2002).

\section{Regional-scale risk assessment methodology for South Africa}

The RRM framework developed by Landis (2005) forms the backbone of the process that we present as the RegionalScale Risk Assessment using the RRM for the management of aquatic ecosystems in South Africa. In this section the 10 steps that make up the RRM are contextualised within the South African water resource management framework. For 
clarification a hypothetical example has been provided to demonstrate the approach.

\section{Step 1: List the important management goals for the region}

To make the RRM as relevant and effective as possible it is important to ensure that the decision-making needs of the environmental managers and stakeholders concerned with the study are met (Landis, 2005). Thus the RRM needs to contribute towards meeting national (e.g. the National Water Resource Strategy - NWRS, DWAF 2004) or more specific information requirements of environmental managers and stakeholders of a particular aquatic ecosystem (e.g. single river or even river reach). On a national scale the RRM can primarily contribute towards meeting the information requirements of the 2 NWRS approaches that are concerned with the management of freshwater aquatic ecosystems, i.e. the Resource Directed Measures (RDM) and Source Directed Controls (SDC) approaches (DWAF, 2004). Thereafter, the application of the RRM in South Africa allows for the objectives/goals of any other stakeholders to be included in the assessment, e.g., generating information requirements as prescribed in the National Environmental Management Act (NEMA) (RSA, 1998b). In order to meet the information requirements and to align the RRM methodology with an established environmental management approach established for South Africa, it is recommended that a stakeholder workshop approach is followed. In these stakeholder workshops the needs of the resource users, environmental managers, regulators and conservationists can be addressed within a legislative context. Following these stakeholder workshops specific management goals can be collectively or individually considered, to allow for the development of suitable endpoints for the study. Endpoints that can be established in an RRM include, for example:

- The maintenance of a preselected ecological integrity state for an ecosystem

- The requirements to conserve a population of a rare of threatened species within a study area

- The requirements of local communities to obtain sufficient water from an aquatic ecosystem to meet the basic human needs

- The maintenance of identified use activities such as subsistence fisheries or the provision of water to maintain selected agricultural or industrial activities, etc.

\section{Step 2: Generate a map and include potential sources and habitats relevant to the established management goals}

The RRM methodology requires a detailed map to facilitate the establishment of relationships between all components of the RRM. The RRM is thus carried out on a regional scale that addresses the spatial distribution of stressors, receptors, habitats and endpoints. The extent of the maps or boundaries should be set according to the established management goals of the RRM (Step 1) and should address all possible variables associated with the various endpoints of the study. This process includes the initial identification and characterisation of potential stressors and sources of stressors occurring within the study area. In addition, important topological features of the study area are included. Thereafter the habitat information for the endpoints of concern is demarcated. A hypothetical example of this process is presented in Fig. 2. In South Africa there are existing geographical information system (GIS) tools such as the Environmental Potential Atlas (DEAT, 2001) that can be used to generate topographical features of the study area, e.g. land use and land cover. The ENPAT data consist of 2 distinct, parallel sets of information, including natural or environmental characteristics and socio-economic factors. The environmental character maps depict geology, land types, soils, vegetation, and hydrology. The socio-economic factors consist of land cover, cadastral aspects and infrastructure, land use and culture (ENPAT, 2001). For an RRM of surface waters, additional spatial data can be obtained from sources including the Department of Water Affairs, Resource Quality Services website (http://www.dwaf.gov.za/iwqs/) (refer to Fig. 2C and Fig. 2D for examples of such maps). In this example, an RRM assessment of the upper catchment of a hypothetical River System A is being undertaken. The management goals (Step 1) of the study, which have been converted into endpoints for the RRM assessment, include the establishment of a sustainableuse management plan for the system. Specific objectives of the study include the establishment of a:

- Management plan for ecosystem users that incorporates guidelines for the management of impacts of activities

- Conservation plan for the study area to maintain the aquatic biodiversity of the area,

- Dedicated conservation plan for the aquatic ecosystems within the protected nature reserve area

- Management plan for the invasive alien fishes in the study area

The study area contains 5 lotic (river) systems and 1 lentic (dam) system that have been demarcated on a map using GIS methods (Fig. 2A). In consideration of the endpoints selected for this study, selected instream and riparian ecosystem components of the surface aquatic ecosystems are addressed. Topological features of the study area are then considered (Fig. 2B) and include some geographical barriers and a ridge line that separates river ecosystems $\mathrm{A}$ and $\mathrm{B}$ from $\mathrm{C}$ and $\mathrm{D}$. According to these topological features, 4 habitat segments of the study area were identified and demarcated. Thereafter, additional spatial information including catchment and ecoregion boundaries is considered (Fig. 2C and D). The land-use and potential ecosystem-use activities that may have an impact on the endpoints (i.e. produce stressors) are then identified and demarcated (Fig. 2E). Finally, in accordance with the assessment of the stressors that may be impacting on the endpoints of the study, the potential sources of the stressors are indicated (Fig. 2F).

\section{Step 3: Demarcate map into regions based on a combination of the management goals, sources and habitats}

In Step 3, combinations of the management objectives, source information, and habitat data are used to establish geographically-explicit portions or risk regions that can be analysed in a relative manner. The risk scores that are calculated throughout the remainder of the RRM assessment are based on the risk regions established in this step. The boundaries of the risk regions are established after consideration of the habitat segments, and sources of stressors that include the consideration of the pathways of exposure of these stressors, i.e. based on the maps generated in Step 2 (Fig. 2). This ensures that the appropriate sources, stressors and habitats are incorporated into these risk regions (Landis, 2005). In this regard it may be 

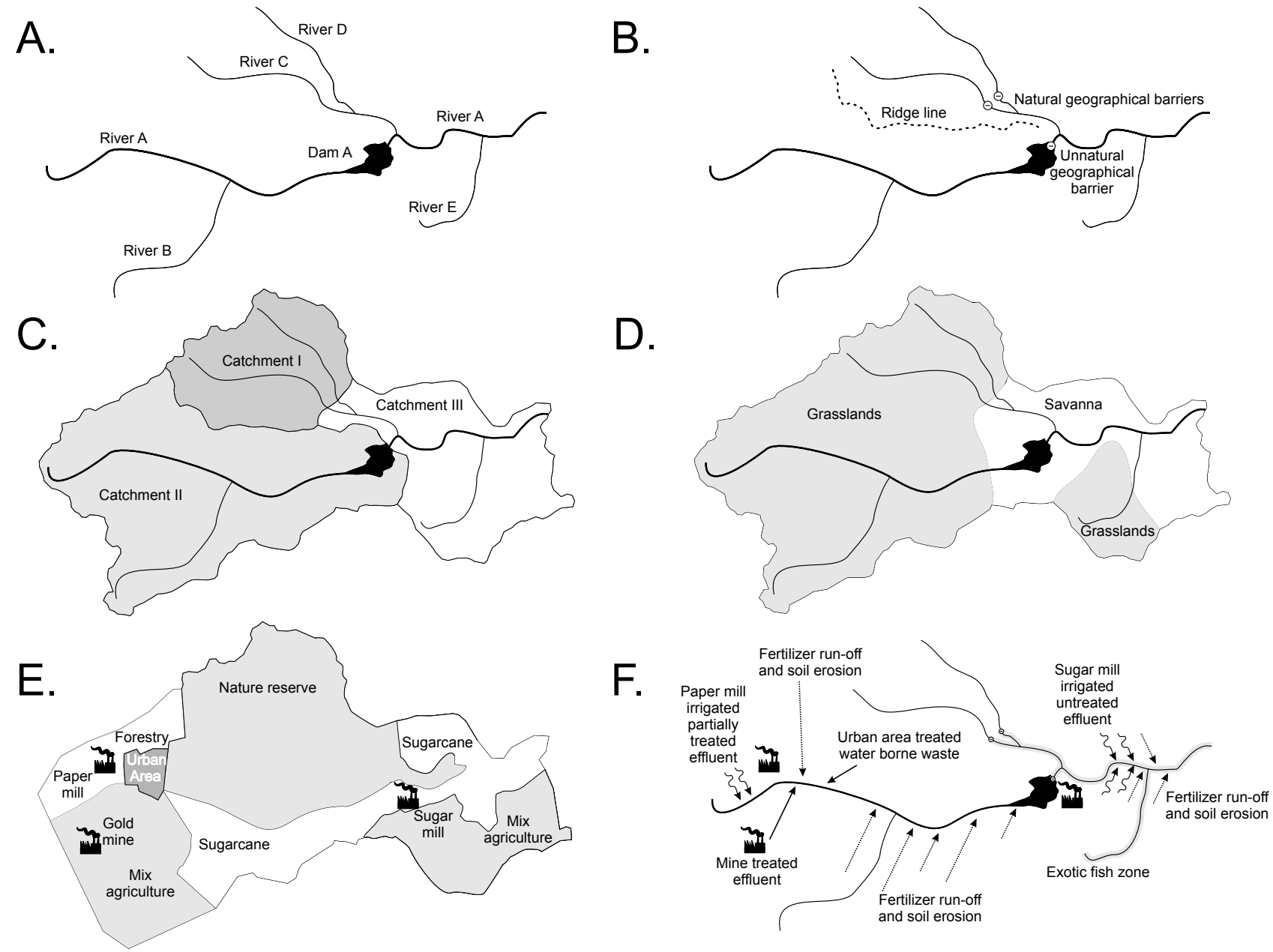

Figure 2

Hypothetical example to generate a map for an RRM in Step 2, including a study area presenting habitats of interest $(A)$, important topological features $(B)$, quaternary catchment boundaries $(C)$, ecoregion boundaries $(D)$, scenario of land use including potential activities that produce stressors $(E)$ and potential sources of stressors $(F)$

very important to follow the fate of water, groundwater, soil, and air variables within the landscape to ensure that appropriate sources, stressors and habitats are incorporated into a risk region (Landis, 2005). Using the hypothetical example in Step 2 , risk regions are established (Fig. 3A and B).

\section{Step 4: Construct a conceptual model that links the sources of stressors to receptors and to the assessment endpoints}

The conceptual model delineates the potential relationships between sources, stressors, habitats and endpoints that will be used in the assessment of each risk region (Landis, 2005). A well-constructed and informative conceptual model acts as an extension of the basic framework for the RRM, with sources providing stressors in particular habitats. Initially the information used to establish the maps for the RRM in Step 2 should be considered. Thereafter the conceptual model is constructed through generating resource-use scenarios based on information gathered from stakeholders, various databases (such as the registration database of water users in South Africa), and existing ecological health assessments and/or environmental management reports. A detailed conceptual model can be extremely useful in that it eliminates some stressors, due to lack of exposure pathways, and can lead to the inclusion of
A.
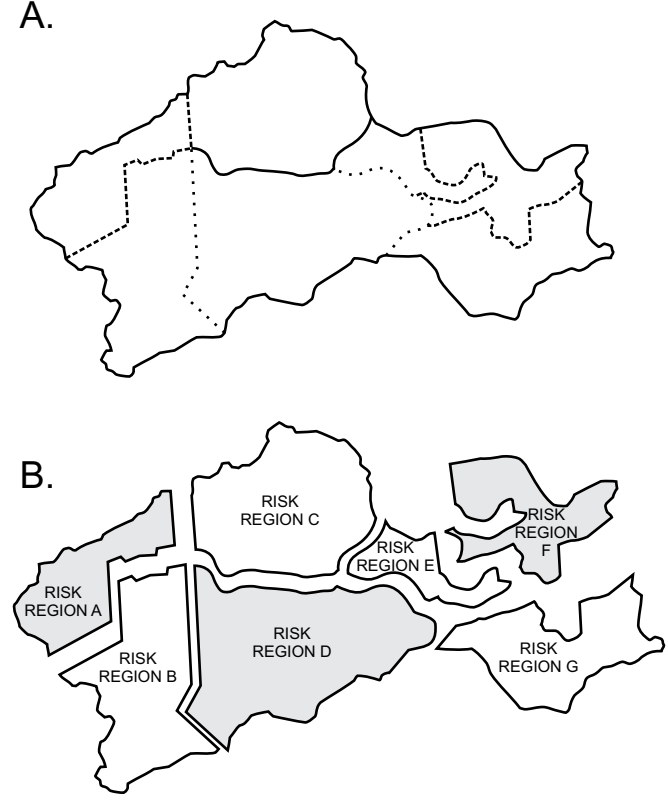

Figure 3

Hypothetical example to undertake Step 3 of the RRM and risk region demarcation following the consideration of sources and habitats in the study area (A), and the resulting 7 risk regions (B) 


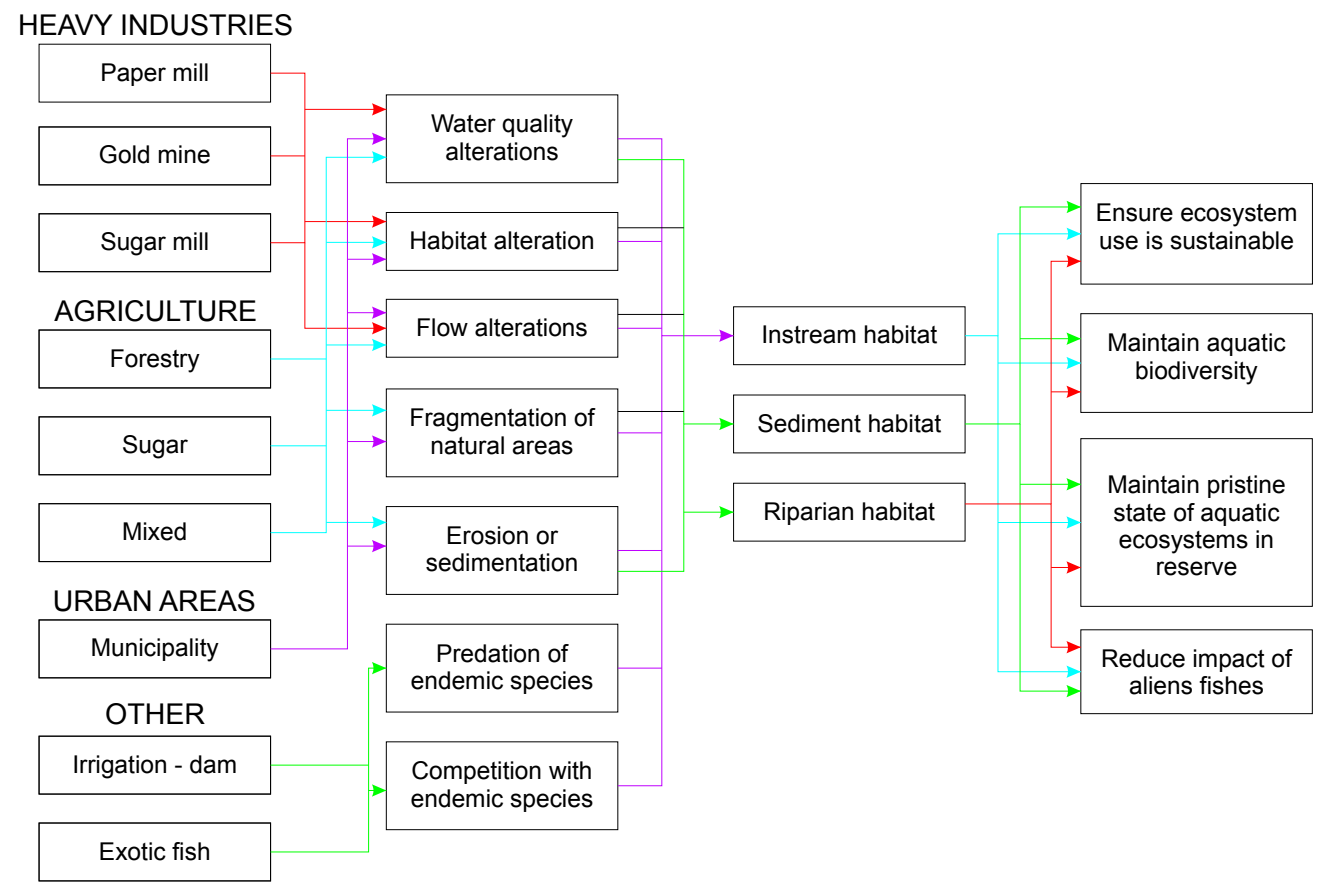

Figure 4 Hypothetical example of the construction of a conceptual model presenting the possible relationships between identified sources, stressors, habitats and endpoints in the assessment other factors that were outside the original scope of the assessment (Landis, 2005). The primary value of a conceptual model is that it allows for the establishment of complex theoretical relationships between stressors and sources that will later be tested within the assessment. This allows for the modification of relationships following the evaluation of uncertainty and the sensitivity assessments (Step 7) to establish a scenario of relationships between stressors and sources. The conceptual model for the RRM assessment scenario based on the hypothetical example in Step 2 is presented in Fig. 4. In this example the potential relationships between the stressors resulting from the heavy industrial, agricultural, urban and other activities in the study area and the habitats and endpoints selected in the study are presented. This established conceptual model will be used in many of the following steps, particularly in Steps 5 and 6 of the RRM.

\section{Step 5: Decide on a ranking scheme to allow the calculation of the relative risk to the assessment endpoints}

Step 5 involves the establishment of a ranking scheme that allows for the calculation of relative risks to each assessment endpoint. The initial process involves the establishment of a ranking scheme, for each source, stressor and habitat, which in turn contributes to the establishment of the relative risks to each assessment endpoint (Landis, 2005). In this step, data are converted into non-dimensional ranks so that the effects of the various stressors on the various endpoints can be measured and compared (Landis, 2005). In the establishment of a ranking scheme, each source/stressor and habitat variable is ranked between sub-areas so as to indicate whether the diversity/abundance or intensity of the variable is high, moderate or low within the context of the region. Ranks are assigned using criteria that are specific to the study region and are generally assigned according to the size and frequency of the sources and the availability of habitat. The traditional RRM approach assigns rankings on a scale of 0 to 6 , with ranks assigned in increments of 2 , where 0 indicates no habitat or source while 2,4 and 6 indicate low, moderate and the greatest amount of habitat or source, respectively (Landis, 2005). The criteria for each non-dimensional ranking system should be chosen in consideration of the available information. In this part of the assessment it is recommended to apply a weight-of-evidence approach (e.g. Burton et al., 2002). In some instances, where adequate concentration, response and fate of stressor data are available to assign ranks to an identified source, this information must be used to establish the criteria for the ranking system (Landis, 2005).

A ranking scheme for source and habitat variables at each risk region of the hypothetical example is presented in Table 2 . The ranks are allocated to sources with the stressor relationships based on the presence of the source within a risk region and possible impacts associated with its location and subsequent downstream impacts. As an example we consider Risk Region A where the paper mill (source) is associated with water quality, habitat and flow alteration stressors (Fig. $4)$. Due to the large number of stressors associated with this source, the highest source rank (6) is allocated to those risk regions close to the activity (Table 2 ). The risk regions that occur downstream of the activity are allocated ranks based on the distance of the particular region from the activity, i.e. decreasing risk ranks of 4 and 2 are allocated to risk regions located directly downstream of the activity, as well as 2 regions downstream of the activity, respectively. The habitat ranks for the same risk region (A) are based on the ecological importance and sensitivity of each habitat in relation to its importance to an ecosystem function and/or the presence of rare or threatened habitats or species.

\section{Step 6: Calculate the relative risks}

Step 6 involves the establishment of exposure and effect filters for the RRM and the integration of the ranks and filters to allow for the calculation of relative risks. 


\begin{tabular}{|c|c|c|c|c|c|c|c|c|c|c|c|}
\hline \multicolumn{12}{|c|}{$\begin{array}{l}\text { TABLE } 2 \\
\text { Overview of the ranking scheme and ranks allocated to source and habitat variables per risk region considered in the } \\
\text { example of the study. }\end{array}$} \\
\hline & Rank 0 & Rank 2 & Rank 4 & Rank 6 & $\underset{\substack{\alpha \\
\alpha}}{\ll}$ & $\begin{array}{l}m \\
\frac{\alpha}{\alpha} \\
\alpha\end{array}$ & $\begin{array}{l}u \\
\frac{\alpha}{\alpha}\end{array}$ & $\begin{array}{l}0 \\
\stackrel{\alpha}{\alpha}\end{array}$ & $\begin{array}{l}\underset{\sim}{\alpha} \\
\stackrel{\alpha}{\alpha}\end{array}$ & $\begin{array}{l}\frac{L}{\alpha} \\
\frac{\alpha}{\alpha}\end{array}$ & $\begin{array}{l}0 \\
\frac{\alpha}{\alpha}\end{array}$ \\
\hline Sources & \multicolumn{3}{|c|}{ Ranking criteria for sources } & & \multicolumn{7}{|c|}{ Source ranks assigned per RR } \\
\hline Paper mill & - & 2 RR below & $1 \mathrm{RR}$ below & Occurs in RR & 6 & 4 & 0 & 2 & 2 & 2 & 0 \\
\hline Gold mine (treated) & - & $1 \mathrm{RR}$ below & Occurs in RR & - & 0 & 4 & 0 & 2 & 2 & 2 & 0 \\
\hline Sugar mill & - & 2 RR below & 1 RR below & Occurs in RR & 0 & 0 & 0 & 0 & 0 & 6 & 0 \\
\hline Forestry & - & - & $1 \mathrm{RR}$ below & Occurs in RR & 6 & 0 & 0 & 4 & 0 & 0 & 0 \\
\hline Sugar plantations & - & - & $1 \mathrm{RR}$ below & Occurs in RR & 0 & 0 & 0 & 6 & 4 & 6 & 0 \\
\hline Mixed agriculture & - & $1 \mathrm{RR}$ below & Occurs in RR & - & 0 & 4 & 0 & 2 & 0 & 2 & 4 \\
\hline Municipality & - & 2 RR below & $1 \mathrm{RR}$ below & Occurs in RR & 0 & 6 & 0 & 4 & 2 & 2 & 0 \\
\hline Irrigation dam & - & 1 RR below & Occurs in RR & - & 0 & 0 & 0 & 4 & 2 & 2 & 0 \\
\hline Exotic fish & - & - & - & Occurs in RR & 0 & 0 & 0 & 0 & 6 & 6 & 6 \\
\hline Habitats & \multicolumn{3}{|c|}{ Ranking criteria for habitats } & & \multicolumn{7}{|c|}{ Habitat ranks assigned per RR. } \\
\hline Instream EIS & None & Low & Med & High & 6 & 6 & 6 & 4 & 2 & 2 & 2 \\
\hline Sediment EIS & None & Low & Med & High & 6 & 6 & 6 & 6 & 2 & 2 & 2 \\
\hline Riparian EIS & None & Low & Med & High & 4 & 4 & 4 & 4 & 4 & 4 & 4 \\
\hline
\end{tabular}

Note: (RR) Refers to risk region

(EIS) Measure of ecological importance and sensitivity of habitat

(1 RR below) Rank allocated to RR located directly downstream of activity

(2 RR below) Rank allocated to RR located two regions downstream of activity

\section{Establishment of exposure and effect filters}

In this step, filters are used to determine the relationships between the risk components, including the source, habitat and impacts to assessment endpoints. A filter is a numerical weighting factor ( 0 or 1$)$ that indicates either none or a low (0) or high (1) probability that a relationship of risk exists (Landis, 2005). According to Landis (2005), 2 types of filters are used in RRM assessments, namely, an exposure filter and an effect filter.

The exposure filter screens the source and habitat types for the combinations most likely to result in exposures, i.e., receptors in the habitat will come into contact with stressors generated by the source. The effect filter screens the source and habitat combinations for those most likely to affect an assessment endpoint or objective of the study.

Exposure filters are established by considering which of the stressors are produced by the sources (Landis, 2005). Two sequential questions about each stressor in relation to specific source-habitat combinations are considered, including:

- Will the source release or cause a stressor?

- Will the stressor then occur and persist in the habitat?

If either of these questions results in a positive answer, then the value of 1 is assigned to the filter associated with the sourcehabitat combination. If the answer to either question is 'no' then the value of 0 is assigned. In the case of indirect relationships or potential relationships that are unclear, a value of 0.5 is assigned to a filter as opposed to a value of 1 .

Effect filters are established in a similar way to exposure filters. However a separate filter for each assessment endpoint is established. It is important to consider the management goals of the study at this point to ensure that the variables of the endpoints result in effective conservation, maintenance or management towards the goals. At this stage the effect filters can be established to ensure that these management goals are addressed. The questions asked to develop the effect filers are:

- Will the source release stressors known to cause this particular effect on the endpoint?
- Are receptors associated with the endpoint sensitive to the stressor in the habitat?

If the answer to both questions is 'yes', then a value of 1 is assigned to the filter associated with the source-habitat and endpoint combination. If the answer to either question is 'no', then a value of 0 is assigned. As with the exposure filter, this approach allows for the consideration of indirect relationships or potential relationships that are unclear by assigning a score of 0.5 to a filter as opposed to a value of 1 . In some instances, when a source-habitat-endpoint relationship is beneficial to ecosystem structure and function, the exposure filter can be assigned a negative (-) value to reflect this in the filtering process. Some examples of exposure and effect filters that could be allocated to source-habitat relationships and sourcehabitat-endpoint relationships for the hypothetical example are presented in Table 3 and Table 4. In particular, the source filter used in the example here demonstrates that activities associated with the paper mill are directly considered as resulting in stressors that would occur within the instream habitat. In order to score these relationships, the conceptual model and available information pertaining to the dynamics of the ecosystems that may influence the relationship need to be considered. Examples of ecosystem dynamics variables that can be considered at this point include the effluent mitigation potential of a system, the dilution potential for wastes in a system and/or the tolerances of an ecosystem to physical habitat alterations. To expand on this concept, a different ranking system and exposure filter would be used to establish exposure relationships between sources and habitats in a healthy, functioning, productive aquatic ecosystem that has a high assimilation capacity compared to a system that is not productive and is sensitive to water quality stressors. In addition, the exposure filter relationships between sources and habitats in a large system with a large discharge would be scored differently to a system with a comparatively smaller discharge. Finally, a system with a stable habitat and high discharge would be more tolerant to habitat 


\begin{tabular}{|c|c|c|c|c|}
\hline \multicolumn{5}{|c|}{$\begin{array}{c}\text { TABLE } 3 \\
\text { Example of the exposure filters allocated to source } \\
\text { and habitat relationships in the hypothetical example } \\
\text { considered in this study }\end{array}$} \\
\hline Source & Habitat & $\begin{array}{c}\text { Source } \\
\text { causing } \\
\text { stressor } \\
\text { to occur } \\
\text { within } \\
\text { habitat? }\end{array}$ & $\begin{array}{c}\text { Stressor } \\
\text { persisting } \\
\text { in habitat? }\end{array}$ & Filter \\
\hline Paper mill & \multirow{9}{*}{ 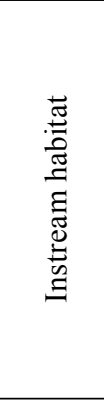 } & 1 & 1 & 1 \\
\hline Gold mine (treated) & & 1 & 1 & 1 \\
\hline Sugar mill & & 1 & 1 & 1 \\
\hline Forestry & & 1 & 1 & 1 \\
\hline Sugar plantations & & 1 & 1 & 1 \\
\hline Mixed agriculture & & 1 & 0.5 & 0.5 \\
\hline Municipality & & 1 & 0.5 & 0.5 \\
\hline Irrigation dam & & 1 & 1 & 1 \\
\hline Exotic fish & & 1 & 1 & 1 \\
\hline Paper mill & \multirow{9}{*}{ 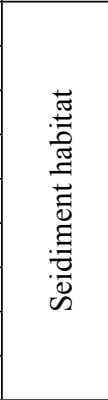 } & 1 & 1 & 1 \\
\hline Gold mine (treated) & & 1 & 1 & 1 \\
\hline Sugar mill & & 1 & 0.5 & 0.5 \\
\hline Forestry & & 1 & 1 & 1 \\
\hline Sugar plantations & & 1 & 1 & 1 \\
\hline Mixed agriculture & & 1 & 1 & 1 \\
\hline Municipality & & 1 & 0.5 & 0.5 \\
\hline Irrigation dam & & 1 & 1 & 1 \\
\hline Exotic fish & & 0 & 0 & 0 \\
\hline Paper mill & \multirow{9}{*}{ 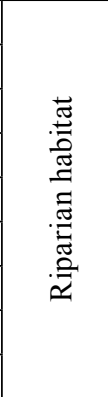 } & 0 & 0 & 0 \\
\hline Gold mine (treated) & & 0 & 0 & 0 \\
\hline Sugar mill & & 0.5 & 1 & 0.5 \\
\hline Forestry & & 1 & 1 & 1 \\
\hline Sugar plantations & & 1 & 1 & 1 \\
\hline Mixed agriculture & & 1 & 1 & 1 \\
\hline Municipality & & 1 & 0.5 & 0.5 \\
\hline Irrigation dam & & 1 & 1 & 1 \\
\hline Exotic fish & & 0 & 0 & 0 \\
\hline
\end{tabular}

impacts such as siltation compared to a shallow, slow-flowing system with an alluvial bed, and would therefore require a different scoring approach for exposure filters.

Similar ecosystem dynamics considerations must be accounted for in the allocation of effects filters. In the hypothetical example we assumed that the irrigation dam would, for example, impact on available habitat and/or water quality regimes of the system resulting in a negative response of the ecosystem. This would affect the sustainable use of the resources associated with the ecosystem (endpoint). The relationship of the activities associated with an irrigation dam (source) and the instream habitat (habitat) with the maintenance of sustainable use of the ecosystem resources (endpoint) has been allocated a positive filter score of $(+1)$, indicating that a high potential exists that the activity would result in impacts that would pose a risk. Conversely, when considering the same source and habitat relationship with another endpoint such as the maintenance of aquatic biodiversity, the effect filter scoring system is constructed such that potentially beneficial impacts would result where the modified habitat may allow for the establishment of refugia and an increase in aquatic biodiversity. In this case the relationship is filtered with a negative score (-1).

\section{Integrating ranks and filters}

In this step ranks and weighting factors are now combined through multiplication. The results are a relative estimate of risk in each risk region. Final risk scores (RS) are calculated for each risk region by multiplying the ranks by the appropriate weighting factor, as indicated in the following equation (Eq. (1)):

$$
R S=S i j \times H i j \times W j k
$$

where:

$$
\begin{aligned}
i= & \text { the RRs or sub-area series (Region } 1,2,3, \text { etc.) } \\
j= & \text { the source series (discharge..., shoreline activity) } \\
k= & \text { the habitat series (mudflat..., stream mouth) } \\
S i j= & \text { rank chosen for sources (i) between subareas (j) } \\
H i k= & \text { rank chosen for habitats between subareas } \\
W j k= & \text { weighting factor established by the exposure or } \\
& \text { effect filter }
\end{aligned}
$$

The result is a matrix of risk scores related to the relative exposure or effects associated with the source and habitat in each risk region. The potential risk resulting from a specific source (Eq. (2)) and occurring within a specific habitat (Eq. (3)) can be summarised for each sub-area by adding the related scores:

$$
\begin{aligned}
& R S_{\text {source }}=\sum(S i j \times H i k \times W j k) \text { for } j=1 \text { to } n \text { source } \\
& R S_{\text {habitat }}=\sum(S i j \times H i k \times W j k) \text { for } k=1 \text { to } n \text { habitat }
\end{aligned}
$$

To illustrate the type of risk scores that are generated in an RRM assessment, a summary of the $R S$ (Eq. (1)) for each risk region considered in the hypothetical example, as well as the $R S_{\text {source }}$ (Eq. (2)) and $R S_{\text {habitat }}$ (Eq. (3)) for the study, is presented in Table 5. Note that $R S$ values are relative to each other and as such the values obtained in the example would only be meaningful when considered in the context of this case study. Findings from the hypothetical case study are that a wide range of final risk scores per risk region was obtained (0 to 776). In an RRM assessment various approaches can be incorporated to establish risk-level thresholds (Landis and Wiegers, 1997; Landis, 2005). These include the consideration of the risk outcomes in relation to one another where greater $R S$ for a particular risk region or habitat or endpoint would suggest greater risk of impact and thus warrant a higher risk level (Landis and Wiegers, 1997). Another approach involves the consideration of reasonable maximum and minimum ranges of risk that can be produced by an established RRM. This may include the use of professional judgement to alter stressor and habitat ranks to reflect reasonable maximum and minimum scenarios (Landis, 2005). In the example, $R S$ values of above 500 are considered to be associated with high levels of risk, levels between 250 and 500 were considered to result in moderate risk levels, and RS values of less than 250 result in low risk levels (Fig. 5). The combination of multiple sources resulting in multiple stressors in the example study area would result in highest risk of impacts occurring in Risk Regions D and F. Thereafter, moderate risks of impact occur within Risk Regions A, B and E. Finally, low risks of impacts occur in Risk Region $\mathrm{G}$ and no risks of impacts were determined to occur within Risk Region C.

When considering total risks over all regions, the relatively high risks posed by sources $\left(R S_{\text {source }}\right)$ were found to be, in order of magnitude (Table 5), sugar plantations, paper mills, forestry plantations, and exotic fish. When considering the sources per risk region, the agricultural activities, including the sugar 


\begin{tabular}{|c|c|c|c|c|c|c|c|c|c|c|c|c|c|}
\hline \multicolumn{14}{|c|}{$\begin{array}{c}\text { TABLE } 4 \\
\text { Example of the effect filters allocated to source, habitat and endpoint relationships in the hypothetical example } \\
\text { considered in this study }\end{array}$} \\
\hline \multirow[t]{2}{*}{ Source } & \multirow[b]{2}{*}{$\frac{\pi}{\frac{\pi}{\pi}}$} & \multicolumn{3}{|c|}{$\begin{array}{c}\text { Ensure ecosystem use is } \\
\text { sustainable }\end{array}$} & \multicolumn{3}{|c|}{$\begin{array}{l}\text { Maintain aquatic } \\
\text { biodiversity }\end{array}$} & \multicolumn{3}{|c|}{$\begin{array}{l}\text { Maintain pristine state of } \\
\text { aquatic ecosystems in } \\
\text { Reserve }\end{array}$} & \multicolumn{3}{|c|}{$\begin{array}{l}\text { Reduce impact of alien } \\
\text { fishes }\end{array}$} \\
\hline & & 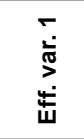 & 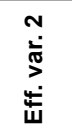 & 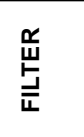 & 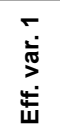 & 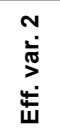 & 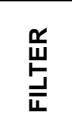 & 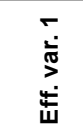 & 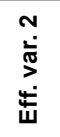 & 営 & 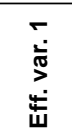 & 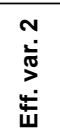 & 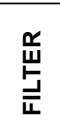 \\
\hline Paper mill & \multirow{9}{*}{ 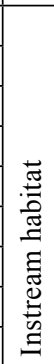 } & 1 & 1 & 1 & 1 & 1 & 1 & 1 & 1 & 1 & 0 & 0 & 0 \\
\hline Gold mine (treated) & & 1 & 1 & 1 & 1 & 1 & 1 & 1 & 1 & 1 & 0 & 0 & 0 \\
\hline Sugar mill & & 1 & 1 & 1 & 1 & 1 & 1 & 1 & 1 & 1 & 0 & 0 & 0 \\
\hline Forestry & & 1 & 1 & 1 & 1 & 1 & 1 & 1 & 1 & 1 & 0 & 0 & 0 \\
\hline Sugar plantations & & 1 & 1 & 1 & 1 & 1 & 1 & 1 & 1 & 1 & 0 & 0 & 0 \\
\hline Mixed agriculture & & 1 & 1 & 1 & 1 & 1 & 1 & 1 & 1 & 1 & 0 & 0 & 0 \\
\hline Municipality & & 1 & 1 & 1 & 1 & 1 & 1 & 1 & 1 & 1 & 0 & 0 & 0 \\
\hline Irrigation dam & & 1 & 0 & 0 & -1 & 1 & -1 & -1 & 1 & -1 & 0.5 & 0.5 & 0.5 \\
\hline Exotic fish & & 1 & 1 & 1 & 1 & 1 & 1 & 1 & 1 & 1 & 1 & 1 & 1 \\
\hline Paper mill & \multirow{9}{*}{ 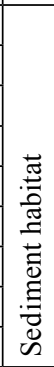 } & 0.5 & 1 & 0.5 & 1 & 1 & 1 & 1 & 1 & 1 & 0 & 0 & 0 \\
\hline Gold mine (treated) & & 0.5 & 1 & 0.5 & 1 & 1 & 1 & 1 & 1 & 1 & 0 & 0 & 0 \\
\hline Sugar mill & & 1 & 1 & 1 & 0.5 & 1 & 0.5 & 0.5 & 1 & 0.5 & 0 & 0 & 0 \\
\hline Forestry & & 0.5 & 1 & 0.5 & 1 & 1 & 1 & 1 & 1 & 1 & 0 & 0 & 0 \\
\hline Sugar plantations & & 1 & 1 & 1 & 1 & 1 & 1 & 1 & 1 & 1 & 0 & 0 & 0 \\
\hline Mixed agriculture & & 0.5 & 0 & 0 & 0.5 & 0 & 0 & 0.5 & 0 & 0 & 0 & 0 & 0 \\
\hline Municipality & & 0.5 & 0.5 & 0.5 & 0.5 & 0.5 & 0.25 & 0.5 & 0.5 & 0.25 & 0 & 0 & 0 \\
\hline Irrigation dam & & 0.5 & 1 & 0.5 & 0 & 1 & 0 & 0 & 1 & 0 & 0 & 0 & 0 \\
\hline Exotic fish & & 0 & 0 & 0 & 1 & 1 & 1 & 1 & 1 & 1 & 0 & 0 & 0 \\
\hline Paper mill & \multirow{9}{*}{ 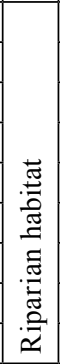 } & 0.5 & 1 & 0.5 & 0 & 0 & 0 & 0 & 0 & 0 & 0 & 0 & 0 \\
\hline Gold mine (treated) & & 0 & 1 & 0 & 0 & 0 & 0 & 0 & 0 & 0 & 0 & 0 & 0 \\
\hline Sugar mill & & 0 & 0.5 & 0 & 0.5 & 1 & 0.5 & 0.5 & 1 & 0.5 & 0 & 0 & 0 \\
\hline Forestry & & 1 & 1 & 1 & 1 & 1 & 1 & 1 & 1 & 1 & 0 & 0 & 0 \\
\hline Sugar plantations & & 1 & 1 & 1 & 1 & 1 & 1 & 1 & 1 & 1 & 0 & 0 & 0 \\
\hline Mixed agriculture & & 1 & 1 & 1 & 0.5 & 1 & 0.5 & 0.5 & 1 & 0.5 & 0 & 0 & 0 \\
\hline Municipality & & 1 & 0.5 & 0.5 & 0.5 & 1 & 0.5 & 0.5 & 1 & 0.5 & 0 & 0 & 0 \\
\hline Irrigation dam & & 0.5 & 1 & 0.5 & 0 & 0 & 0 & 0 & 0 & 0 & 0 & 0 & 0 \\
\hline Exotic fish & & 0 & 0 & 0 & 0 & 0 & 0 & 0 & 0 & 0 & 0 & 0 & 0 \\
\hline
\end{tabular}

Note: (Eff. var. 1) Effect variable querying whether source stressor relationship is known to have an effect on the endpoint?

(Eff. var. 2) Effect variable querying whether endpoint is known to be sensitive to stressor in the habitat?

\begin{tabular}{|l|c|c|c|c|c|c|c|c|}
\hline \multicolumn{7}{|c|}{ TABLE 5 } \\
\multicolumn{7}{|c|}{ Summary of all of the risk scores obtained from the example used in this study } \\
\hline & RR A & RR B & RR C & RR D & RR E & RR F & RR G & \\
\hline Final risk scores $(\boldsymbol{R S}$, Eq.(1)) & $\mathbf{4 6 8}$ & $\mathbf{4 2 2}$ & $\mathbf{0}$ & $\mathbf{6 7 8}$ & $\mathbf{4 9 0}$ & $\mathbf{7 7 6}$ & $\mathbf{2 1 2}$ & \\
\hline Risk scores for sources $\left(\boldsymbol{R S}_{\text {saurces }}\right.$, Eq.(2)) & & & & & & & & TOTALS \\
\hline Paper mill & 198 & 132 & 0 & 66 & 66 & 66 & 0 & $\mathbf{5 2 8}$ \\
\hline Gold mine (treated) & 0 & 132 & 0 & 66 & 66 & 66 & 0 & $\mathbf{3 3 0}$ \\
\hline Sugar mill & 0 & 0 & 0 & 0 & 0 & 156 & 0 & $\mathbf{1 5 6}$ \\
\hline Forestry & 270 & 0 & 0 & 180 & 0 & 0 & 0 & $\mathbf{4 5 0}$ \\
\hline Sugar plantations & 0 & 0 & 0 & 288 & 192 & 288 & 0 & $\mathbf{7 6 8}$ \\
\hline Mixed agriculture & 0 & 68 & 0 & 34 & 0 & 34 & 68 & $\mathbf{2 0 4}$ \\
\hline Municipality & 0 & 90 & 0 & 60 & 30 & 30 & 0 & $\mathbf{2 1 0}$ \\
\hline Irrigation dam & 0 & 0 & 0 & -16 & -8 & -8 & 0 & $\mathbf{- 3 2}$ \\
\hline Exotic fish & 0 & 0 & 0 & 0 & 144 & 144 & 144 & $\mathbf{4 3 2}$ \\
\hline Risk scores for habitats $\left(\boldsymbol{R S}_{\text {habitats }}\right.$, Eq.(3)) & & & & & & & & TOTALS \\
\hline Instream habitat & 216 & 234 & 0 & 270 & 288 & 450 & 180 & $\mathbf{1 6 3 8}$ \\
\hline Sediment habitat & 180 & 138 & 0 & 252 & 144 & 216 & 0 & $\mathbf{9 3 0}$ \\
\hline Riparian habitat & 72 & 50 & 0 & 156 & 58 & 110 & 32 & $\mathbf{4 7 8}$ \\
\hline
\end{tabular}




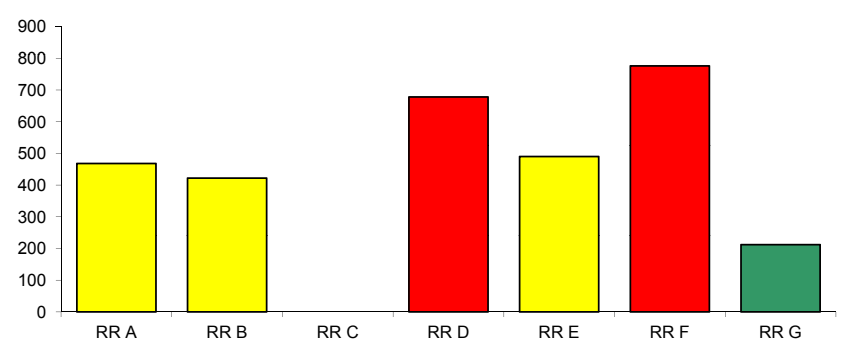

Figure 5

Graphical representation of the final risk scores (RS) obtained per region in the study area. Red bars present relatively high risk, yellow bars present moderate relative risk and the green bar represents low relative risk.

plantations and the forestry activities, pose the highest risk in Regions A, D and F (Fig. 6). The dam in the study area poses a negative risk in risk Regions $\mathrm{D}, \mathrm{E}$ and $\mathrm{F}$, a result interpreted as beneficial in these regions.

The greatest risk posed to habitats $\left(R S_{\text {habita }}\right)$ occurs primarily in the instream habitats, followed by the substrate (sediment), with the riparian habitats being exposed to the lowest risks. The greatest risks posed to the instream habitats occur within Risk Region F, with high risks in Regions E, D, B and A, in order of severity (Fig. 7). The sediment habitat and riparian habitats are at most risk in Risk Region D.
Finally, the risk outcomes need to be considered in relation to the established endpoints for the study area. In ensuring sustainable ecosystem resource utilisation, management plans for all activities, excluding the dam, should be established, with priority given to the sugar plantations, paper mill, forestry plantations and exotic fish. Management actions should be focused on Risk Regions A, B, D, E and F. The instream habitats are most sensitive to the risk of impacts from the sources considered in the study and, as such, maintaining the integrity of these habitats should be prioritised. The hypothetical RRM shows that the risks to the maintenance of aquatic biodiversity in the study area and the maintenance of a pristine ecosystem state in the nature reserve are similar. The maintenance of aquatic biodiversity was found to be important through the management of sources in areas where sensitive habitats occur. This includes the management of the stressors associated with the sugar plantation, forestry and the paper-mill activities in Risk Regions D, E and F. The risks associated with alien fishes in Risk Regions E, F and G were positively affected by the barriers which could be maintained. Similarly, the nature reserve can be considered to be a refugium for the maintenance of the aquatic biodiversity and therefore meets the endpoint that requires that the aquatic ecosystem association with the reserve be maintained. In addition, in order to meet the overall study area endpoint, i.e., to maintain aquatic biodiversity, the nature reserve should be considered to be a refugium and therefore conservation of this reserve should receive high priority.

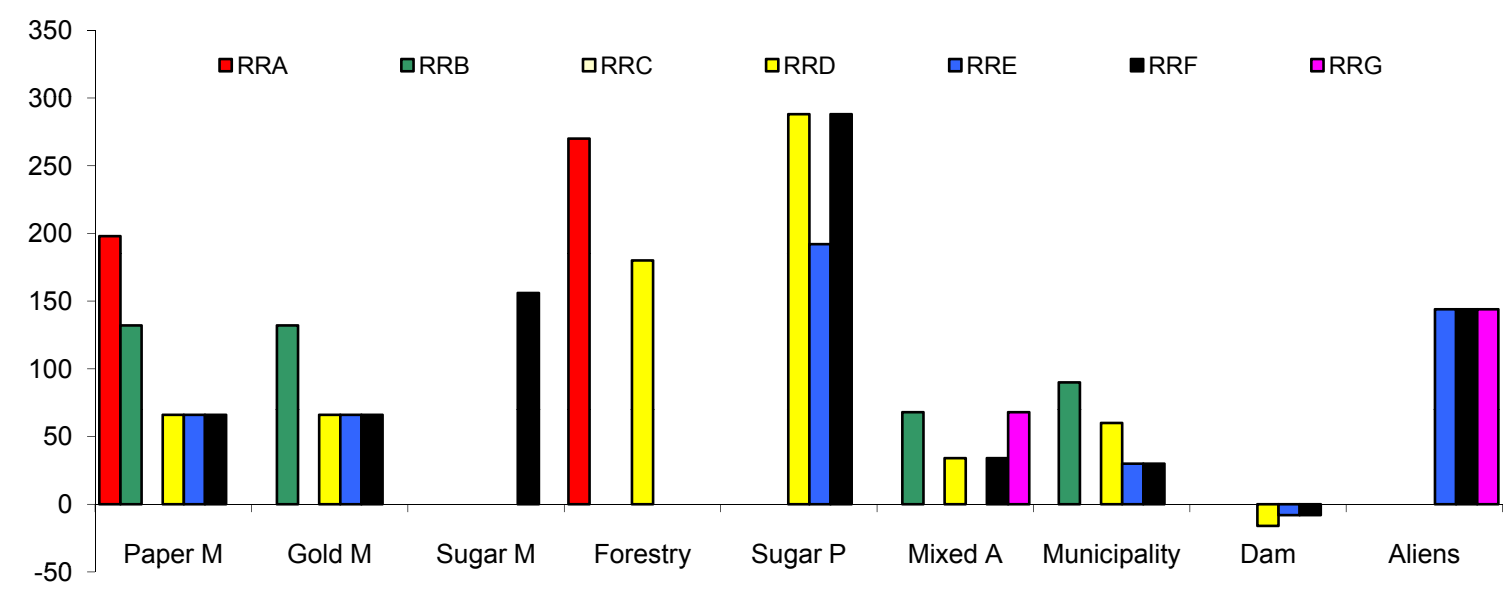

Figure 6

Graphical representation of the total risk per risk region for all of the sources considered in the study

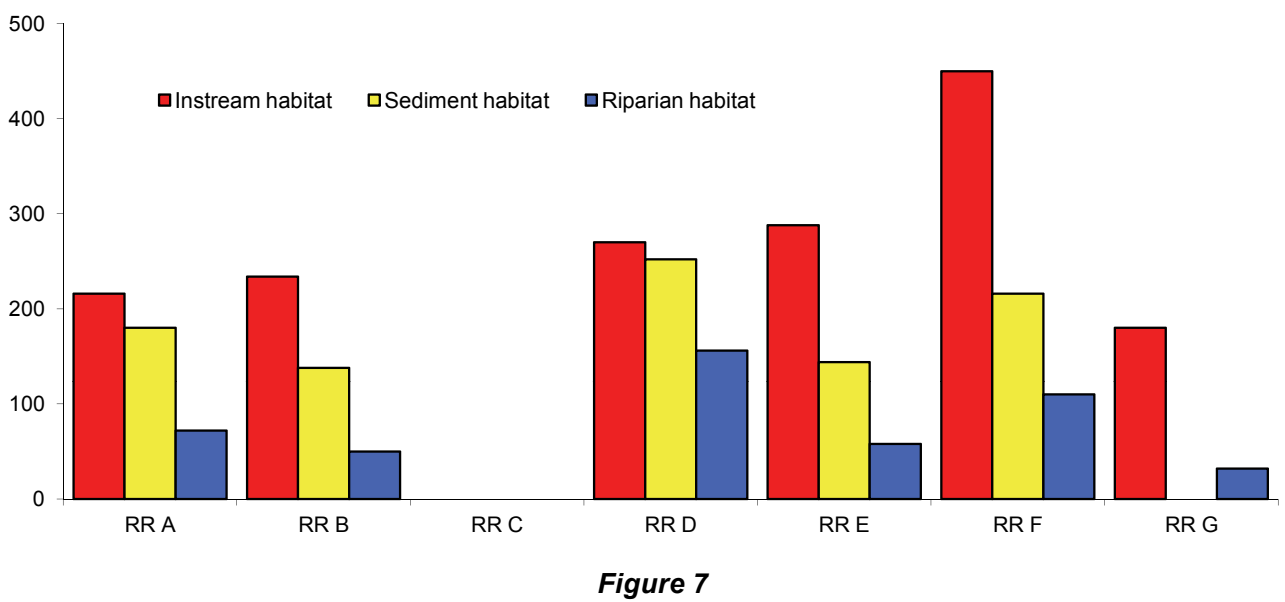

Graphical representation of the total risk posed to each habitat per risk region considered in the hypothetical example 
Finally, the outcomes show that there is very low risk from and, accordingly, no value in managing, the alien invasive fishes in Risk Regions A-D, apart from preventing the further distribution of alien species into these risk regions. In Regions $\mathrm{E}$ and $\mathrm{F}$, however, the importance of managing alien invasive fishes as a source of stressors is moderate- to high, as moderate- to highrisk scores were obtained.

\section{Step 7: Evaluate uncertainty and sensitivity of the relative rankings}

\section{Uncertainty}

When implementing this RRM model it is important to address issues that may cause uncertainty or influence the confidence of the outcomes regarding the risk characterisation of the study. This includes, for example, the use of professional judgment in determination of risk thresholds. In a RRM uncertainties of each component need to be tracked and accounted for in the risk assessment process. The RRM methodology allows for the use of a variety of quantitative methods, including the popular Monte Carlo permutation process which is employed to provide a range of values to simulate uncertainty (Landis, 2005; Colnar and Landis, 2007). This is a probabilistic approach that quantifies the change in model outputs or risk scores as a function of model inputs or ranks and filters (Colnar and Landis, 2007). The approach involves the initial classification of uncertainty for each filter component and rank as low, medium and high, based on the confidence of the assigned values according to available information. Thereafter the ranks and filter components with medium and high classifications are assigned with discrete statistical distributions to represent the uncertainty. The range of statistical distributions used to address the uncertainty of each rank and filter must be documented. The ranks and filter components with low uncertainty classifications retain their original values. After the uncertainty classifications are assigned, the Monte Carlo simulations can be run using sufficient iterations, usually $>1000$, to account for all variability in the model (Colnar and Landis, 2007).

Other single-component analyses techniques, exposurepathway analyses, and random-component analyses to address uncertainty in RRM assessments can be implemented (Obery and Landis, 2002). The single-component analyses include the standardisation of individual stressors in each of the risk regions to test the sensitivity of the model. Exposure-pathway analyses can be undertaken by testing the effect of including or excluding pathways with weak relationships in the conceptual model by altering the exposure filter score for these pathways. This is justified in that only pathways demonstrating a strong relationship between the stressors and habitat and the habitat and endpoint should be evaluated during the risk characterisation. Random-component analysis can be incorporated to evaluate model bias by assigning random numbers during sufficient simulations to stressors and habitats for each risk region (Landis, 2005).

\section{Sensitivity}

Model sensitivity analyses test the influence of individual parameters and the range of parameter values in a RRM model (Colnar and Landis, 2007). In these evaluations correlation coefficients are generated to rank model parameters according to their contribution to prediction uncertainty. High-ranked parameters are those of importance in influencing uncertainty within the model (Colnar and Landis, 2007). Various statistical methods can be used to carry out correlation coefficients, including Crystal Baal ${ }^{\circledR} 2000$ software, for example (Colnar and Landis, 2007).

\section{Step 8: Generate testable hypotheses for future field and laboratory investigation to reduce uncertainties and to confirm the risk rankings}

To reduce uncertainties and to confirm the risk rankings of the RRM, suitable hypotheses for field and laboratory investigations are established. Using the outcomes of Steps 6 and 7 the RRM can generate predictions of patterns in the landscape and estimates of risk to the endpoints of the assessment (Landis, 2005). Testable hypotheses can then be generated to evaluate these predictions. By testing and accepting selected hypotheses generated by the risk assessment the confidence of the outcomes is increased. This in turn increases the confidence of the risk assessors, stakeholders and decision makers in using the risk outcomes for environmental management (Landis, 2005). To illustrate this, a range of hypotheses can be established to validate the outcomes of the RRM assessment for the hypothetical example including:

- Due to the low risk being posed to Risk Region C, the ecological integrity of the aquatic ecosystems and associated biodiversity in this region would be better than the integrity state of the aquatic ecosystems in regions $\mathrm{G}, \mathrm{B}, \mathrm{A}$, $\mathrm{D}, \mathrm{E}$ and $\mathrm{F}$.

- Stressors associated with the sugar plantation will result in the greatest impact on the ecological structure and function of the aquatic ecosystems associated with Risk Regions D, $\mathrm{F}$ and then $\mathrm{E}$.

- The ecological integrity of the sediment habitats in Risk Region D should be high and comparable to the ecological integrity of the sediment habitats in Region C.

\section{Step 9: Test hypothesis established in Step 8}

Hypotheses can be tested using a variety of local and or internationally accepted or validated lines-of-evidence (sensu Fairbrother, 2003). Lines-of-evidence can include a range of field, mesocosm and/or laboratory test methods. Ideally, lines-of-evidence methods should be selected that can test established risk estimates generated in the RRM. This often includes the assessments of the ecological state of biological responder communities in different risk regions. The states of various ecosystem source/stressor driver variables identified in the RRM, such as water and sediment physicochemical quality, habitat availability and state, and flow states (timing, volume and duration of flows), can also be included. Often other procedures are required that can make predictions based on the known concentrations of toxicants and then in situ sampling is carried out to confirm effect or no-effect of the identified toxicants. In South Africa, many lines-of-evidence methodologies have been established that can be incorporated into an RRM to test risk hypotheses. These lines-of-evidence methodologies include, for example, the eco-classification tools that are extensively used in the National River Health Programme of South Africa and in the determination of the ecological Reserve (DWAF, 2004; Kleynhans and Louw, 2007). Additional ecotoxicological lines-of-evidence procedures that consider different levels of biological organisation (Wepener et al., 2011) can also be included in an RRM assessment. These procedures include a range of biomarker, bioaccumulation, histopathology, bioassay and various multivariate statistical methods that consider changes in structures of communities (O'Brien et al., 
2009). Following the testing of risk hypotheses, there is often a need to rework the risk assessment in order to reduce uncertainty, or to rectify a stressor-habitat-effect linkage that may be identified to be incorrect. Testing the risk predictions allows feedback into the assessment process, improving future predictions (Landis, 2005).

\section{Step 10: Communicate the results in a fashion that portrays the relative risk and uncertainty in response to the management goals}

The outcomes of the RRM assessments, irrespective of the scientific validity, are of no use unless these outcomes are clearly communicated to the stakeholders and decision makers who commissioned the study. A variety of tools are available to assist in the communication of the outcomes of the RRM and careful attention must be paid to ensure that the relevant stakeholders of any RRM are presented with information that can easily be understood at different levels of complexity, specific to the relevant audiences of the stakeholder groups. To establish and continue with the development of the RRM methodology in South Africa, it is important that the application and findings of local RRM case studies are published in peer-reviewed literature and/or made available to the stakeholder groups.

\section{Closing remarks}

This RRM approach that allows for the assessment of multiple stressors in unique habitats on a spatial scale while allowing for the consideration of ecosystem structure and function dynamics can contribute towards the management of local surface ecosystems in South Africa. The approach is intrinsically simple and requires very few assumptions. The RRM approach is not restricted to the requirement for controls or reference sites, or states or assumptions about community dynamics, indirect effects or the linearity of responses (Landis and Wiegers, 1997). In addition, the approach allows for the consideration of stressors for which little information is available. The model or framework of the RRM allows for the consideration of future decision making which is based on the ranking procedures. When implementing the RRM approach it is important that the assumptions included in the process or confidence issues of an assessment are well documented. In addition, sensitivity and uncertainty assessments of the RRM should be prioritised and, where possible, validations of established hypotheses should be undertaken to evaluate risk outcomes. Landis and Wiegers (1997) caution against the misuse and abuse of the ranking approach in a manner which is done in indexing systems. As indicated, ranks are the simplified features that represent variable components of an ecosystem's structure and function. These ranks are not the expressions of real data that could be used in a regression, any more than means of real data can be used in this way (Landis and Wiegers, 1997). The RRM projections are arbitrary unless it can be proven that the assessment is based on rules that are constructed by direct analyses of the ecological structure and function (sensu Landis, 2005). This approach should not be used as a replacement for field and laboratory analyses that generate reliable, factual data, but as a method to incorporate, test and consider the implications associated with scenarios of ecosystem use in the context of ecosystem structure and function.

The use and application of the RRM within South Africa has the potential to provide resource users, resource conservators and regulators of surface aquatic ecosystems with a range of benefits. These benefits include the establishment of a validated, structured methodology that is sensitive to the dynamics of individual case studies, relatively simple to apply, extremely informative, locally applicable and internationally comparable with other RRM assessments. Furthermore, this approach provides direct links between exposure and effects of stressors impacting on a spatial scale and has the ability to address complex multiple stressors impacting on diverse ecosystems. As a result, the approach has the ability to provide individual ecosystem users with information (e.g. water licences) in a manner that can be directly related to and/or address established resource quality objectives for the aquatic ecosystems that the users are associated with. This approach has the potential to substantially contribute towards the effectiveness and efficiency of management of the balance between the use and protection of aquatic ecosystems in South Africa.

\section{Acknowledgements}

While developing this RRM methodology for application in South Africa valuable contributions were made by many of our colleagues, risk assessors and local aquatic ecosystem management stakeholders. In particular, the input provided by Sakkie van der Westhuizen, Wayne Landis, Sebastian Jooste and Neels Kleynhans were of great value. Finally, we would like to gratefully acknowledge valuable comments made by the 2 anonymous reviewers of this paper.

\section{References}

APITZ SE (2011) Conceptualizing the role of sediment in sustaining ecosystem services: Sediment-ecosystem regional assessment (SEcoRA). Sci. Total Environ. DOI:10.1016/j.scitotenv.2011.05.060.

BURTON GA, CHAPMAN PM and SMITH EP (2002) Weight-ofevidence for assessing ecosystem impairment. Hum. Ecol. Risk Assess. 8 (7) 1657-1673.

CHEN JC and LANDIS WG (2005) Chapter 10: Using the Relative Risk Model for a Regional-Scale Ecological Risk Assessment of the Squalicum Creek Watershed. In: Landis WG (ed.) Regional Scale Ecological Risk Assessment: Using the Relative Risk Model. CRC Press, Boca Raton. 195-230.

CLAASSEN M, STRYDOM WF, MURRAY K and JOOSTE S (2001) Ecological Risk Assessment. WRC Report No. TT 151/01. Water Research Commission, Pretoria, South Africa.

COLNAR AM and LANDIS WG (2007) Conceptual model development for invasive species and a regional risk assessment case study: the European Green Crab, Carcinus maenas, at Cherry Point, Washington USA. Hum. Ecol. Risk Assess. 13 120-155.

COOK RB, SUTER GW II and SAIN ER (1999) Ecological risk assessment in a large river-reservoir: 1 . Introduction and background. Environ. Toxicol. Chem. 18 581-588

CORMIER SM, SMITH M and NORTON S (2000) Assessing ecological risk in watersheds: A case study of problem formulation in the Big Darby Creek watershed, Ohio, USA. Environ. Toxicol. Chem. 19 1082-1096.

COSTANZA R, D'ARGE R, DE GROOT R, FARBER S, GRASSO M, HANNON B, NAEEM S, LIMBURG K, PARUELO J, O'NEILL RV, RASKIN R, SUTTON P and VAN DEN BELT M (1997) The value of the world's ecosystem services and natural capital. Nature 387 253-260.

DAVIES B and DAY J (1998) Vanishing Waters. UCT Press, Cape Town.

DEAT (DEPARTMENT OF ENVIRONMENTAL AFFAIRS AND TOURISM, SOUTH AFRICA) (2001) Environmental Potential Atlas (ENPAT). Department of Environmental Affairs and Tourism, Pretoria, South Africa. 
DWAF (DEPARTMENT OF WATER AFFAIRS AND FORESTRY, SOUTH AFRICA) (2004) National Water Resource Strategy: Our Blue Print for Survival ( $1^{\text {st }} \mathrm{edn}$.). Department of Water Affairs and Forestry, Pretoria, South Africa.

FAIRBROTHER A (2003) Lines-of-evidence in wildlife risk assessments. Hum. Ecol. Risk Assess. 9 1475-1491.

HAMAMÉ M (2002) Regional Risk Assessment in Northern Chile Report 2002: 1. Environmental Systems Analysis. Chalmers University of Technology, Göteborg, Sweden.

HART HAYES E and LANDIS WG (2004) Regional ecological risk assessment of a near shore marine environment: Cherry Point, WA. Hum. Ecol. Risk Assess. 10 299-325.

KLEYNHANS CJ and LOUW MD (2007) Module A: EcoClassification and EcoStatus determination in River EcoClassification: Manual for EcoStatus Determination (Version 2). Joint Water Research Commission and Department of Water Affairs and Forestry report. WRC Report No. TT 329/08. Water Research Commission, Pretoria.

LANDIS WG (ed.) (2005) Regional Scale Ecological Risk Assessment: Using the Relative Risk Model. CRC Press. Washington, D.C.

LANDIS WG and WIEGERS JK (1997) Design considerations and suggested approach for regional and comparative ecological risk assessment. Hum. Ecol. Risk Assess. 3 287-297.

LANDIS WG and THOMAS JF (2009) Regional risk assessment as part of the long term receiving water study. Int. Environ. Assess. Manage. 5 (2) 234-247.

LANDIS WG, LUXON M, and BODENSTEINER LR (2000) Design of a relative rank method regional-scale risk assessment with confirmational sampling for the Willamette and McKenzie Rivers, Oregon. In: Price FT, Brix KV and Lane, NK (eds.) Proc. $9^{\text {th }}$ Symposium on Environmental Toxicology and Risk Assessment: Recent Achievements in Environmental Fate and Transport, ASTM STP1381. American Society for Testing and Materials, West Conshohocken, PA. 67-88.

LUXON M (2000) Application of the Relative Risk Model for Regional Risk Assessment to the Upper Willamette River and Lower McKenzie River, OR. M.Sc. Thesis, Western Washington University, Bellingham.

MOOSA V (2001) Preface by the Minister of Water Affairs. In: Claassen M, Strydom WF, Murray K and Jooste S (2001) Ecological Risk Assessment. WRC Report No TT 151/01. Water Research Commission, Pretoria, South Africa.

MORAES R, LANDIS WG and MOLANDER S (2002) Regional risk assessment of a Brazilian rain forest reserve. Hum. Ecol. Risk Assess. 8 1779-1803.

MURRAY K and CLAASSEN M (1999) An interpretation and evaluation of the US Environmental Protection Agency Ecological Risk Assessment Guidelines. Water SA 25 (4) 513-518.
NEL J, MAREE G, ROUX D, MOOLMAN J, KLEYNHANS N, SILBERBAUER M and DRIVER A (2004) South African National Spatial Biodiversity Assessment 2004: Technical Report. Volume 2: River Component. CSIR Report No. ENV-S-I-2004-063. Council for Scientific and Industrial Research, Stellenbosch, South Africa.

O'BRIEN GC, SWEMMER R and WEPENER V (2009) Ecological integrity assessment of fish assemblages of the Matigulu/Nyoni and Umvoti estuaries, KwaZulu-Natal, South Africa. Afr. J. Aquat. Sci. 34 (3) 293-302.

OBERY A and LANDIS WG (2002) Application of the relative risk model for Codorus Creek watershed relative ecological risk assessment: An approach for multiple stressors. Hum. Ecol. Risk Assess. 8 405-428.

PALMER T, BEROLD R, MULLER N and SCHERMAN P (2002) Some for All, Forever. Water Ecosystems and People. WRC Report No. TT 176/02. Water Research Commission, Pretoria, South Africa.

RSA (REPUBLIC OF SOUTH AFRICA) (1998a) National Water Act. No. 36 of 1998. South African Government Gazette 19182. Government Printers, Pretoria.

RSA (REPUBLIC OF SOUTH AFRICA) (1998b) National Environmental Management Act. No. 107 of 1998. South African Government Gazette 19519. Government Printers, Pretoria.

SUTER GW (1993) Ecological Risk Assessment. Lewis Publishers, Chelsea, Michigan.

SUTER GW (2001) Applicability of indicator monitoring to ecological risk assessment. Ecol. Indic. 1 101-112.

THOMAS J (2003) Integration of a relative risk multi-stressor risk assessment with the Ncasi long-term receiving water studies to assess effects at the watershed level, Leaf River, Mississippi. Technical Bulletin No. 867. National Council for Air and Stream Improvement Research, Triangle Park, NC.

USEPA (UNITED STATES ENVIRONMENTAL PROTECTION AGENCY) (1998) Guidelines for Ecological Risk Assessment; Notice Fed. Reg. 6326846-26924. Environmental Monitoring Systems Laboratory, Office of Research and Development, US Environmental Protection Agency, Cincinnati, Ohio.

WALKER R, LANDIS WG, and BROWN P (2001) Developing a regional ecological risk assessment: a case study of the Tasmanian agricultural catchments. Hum. Ecol. Risk Assess. 7 417-439.

WIEGERS JK, FEDER HM, MORTENSEN LS, SHAW DG, WILSON VJ and LANDIS WG (1998) A regional multiple stressor rankbased ecological risk assessment for the fjord of Port Valdez, AK. Hum. Ecol. Risk Assess. 4 1125-1173.

WEPENER V, VAN DYK C, BERVOETS L, O'BRIEN G, COVACI A. and CLOETE Y (2011) An assessment of the influence of multiple stressors on the Vaal River, South Africa. J. Phys. Chem. Earth DOI:10.1016/j.pce.2011.07.075. 
http://dx.doi.org/10.4314/wsa.v38i2.1 Available on website http://www.wrc.org.za ISSN 0378-4738 (Print) $=$ Water SA Vol. 38 No. 2 April 2012 ISSN 1816-7950 (On-line) = Water SA Vol. 38 No. 2 April 2012 